\title{
CONDENSATION OF COLD NEUTRONS - IDEA OF G. A. GAMOW. CHEMICAL PROPERTIES OF THE NEUTRON MATTER AND ITS PLACE IN THE PERIODIC SYSTEM OF ELEMENTS
}

\author{
G. B. Ryazantsev ${ }^{1}$, G. K. Lavrenchenko ${ }^{2}$, I. N. Beckman ${ }^{1}$, I. M. Buntseva ${ }^{1}$, S. S. Nedovesov ${ }^{3}$ \\ ${ }^{1}$ Lomonosov Moscow State University, Leninskie Gory, Moscow, Russia, \\ anis-mgu@rambler.ru \\ ${ }^{2}$ LLC «Institute of Low Temperature Energy Technology», POB188, Odessa, Ukraine, \\ lavrenchenko.g.k.@gmail.com \\ 3 Shevchenko National University of Kyiv, Ukraine,pc.remont.tk@gmail.com
}

\begin{abstract}
Today, the neutron matter and neutron stars are already substantially rooted in the nuclear physics and astrophysics, and it is logical to have their consideration of them in terms of chemical properties and principles of general chemistry. The formation of a neutron substance, in addition to gravitational neutronization, is considered, other mechanisms, such as the condensation of ultracold neutrons (UCN) and neutronization due to a critical increase in the atomic number in the Periodic system of elements (PS). The stability of the neutron substance is substantiated already at the micro level due to Tamm interaction and not only at the macro level due to the gravitational interaction, as it is now considered in astrophysics. A neutron substance is a very concrete physical reality, urgently demanding its rightful place in the PS and studying not only physical, but also chemical, and possibly even in the near future, engineering and technical properties. We also consider the possibility of a "chemical" interaction of UCN with molecules of substances with an odd number of electrons. It is proposed to extend the PS beyond the limits of classical chemical substances and to cover a much wider range of matter in the universe, based on the forgotten ideas of D.I. Mendeleev. Moreover, PS begins with neutron and its isotopes (dineutron, tetraneutrone, etc.) and ends the neutron stellar substance.
\end{abstract}

Keywords: neutron, neutron stars, neutron substance, periodic system of elements, neutronization, Tamm interaction, condensation of UCN.

Сьогодні нейтронна матерія та нейтронні зірки вже істотно вкоренилися в ядерній фізиці і астрофізиці, i логічно їх розглядати 3 точки зору хімічних властивостей і принципів загальної хімії.

Розглянуто створення нейтронної речовини на додаток до гравітаційної нейтронізаціі, по іншим механізмам, таким як конденсація ультрахолодних нейтронів (УХН) і нейтронізаціі через критичне збільшення атомного номера в Періодичній системі елементів (ПС). Стійкість нейтронної речовини затверджується вже на мікрорівні завдяки взаємодії Тамма, а не тільки на макрорівні, зумовленого гравітаційною взаємодією, як це зараз розглядається в астрофізиці.
Слід зазначити, що Г. Гамов вперше розповів про конденсації холодних нейтронів (1946). Рідко згадується ця ідея, яка з часом знайшла застосування в теорії нейтронних зірок. Гамов в 1937-38 рр. Показав, що при стисненні нейтронного газу виникає новий надщільний стан речовини.

Нейтронна речовина - це дуже конкретна фізична реальність, що вимагає законного місця в ПС і вивчення не тільки фізичних, а й хімічних $\mathrm{i}$, можливо, навіть в найближчому майбутньому інженерних і технічних властивостей. Ми також розглядаємо можливість «хімічної» взаємодії УХН з молекулами речовин 3 непарним числом електронів.

Пропонується розширити ПС за межі класичних хімічних речовин і охопити набагато ширше коло матеpiї у Всесвіті, заснований на забутих ідеях Д.І. Менделєєва. Більш того, ПС починається 3 нейтрона і його ізотопів (дінейтрон, тетранейтронов і т. д.) і закінчується нейтронною зоряною речовиною.

Ключові слова: нейтрон, нейтронні зірки, нейтронна речовина, періодична система елементів, нейтронізація, взаємодія Тамма, конденсація УХН.

\section{Introduction}

Neutron matter, from the point of view of General Chemistry, can be formally attributed to chemically simple (i.e., it can not be decomposed further into simpler by chemical means), then inevitably the question arises about the Element, it corresponds to, and its place in the Periodic System (PS). Based on the logic of the Periodic Law $(\mathrm{PL})-($ atomic number $=$ electric charge $)-$ atomic number of neutron matter will correspond to zero, which brings to mind the Dmitri Ivanovich Mendeleev's idea of the zero group and period. D.I.Mendeleyev assumed existence before the hydrogen elements X and Y. Element X (Mendeleev calls it "Newtonium") got its place in the periodic system - in the zero period of the zero group, as the lightest analog of inert gases. In addition, Mendeleev allowed the existence of one more element lighter than hydrogen - the element Y, "Koroniya"(Mendeleev, 1905; Ryazantsev et al., 2014) . It should be noted that even after D.I. Mendeleev's question about "zero" elements was repeat- 
edly raised by many authors both in the past and in the present centuries, however, for brevity we mention only the very first and famous: for example, Ernest Rutherford in 1920 ( Ryazantsev et al., 2014; Kikoin, 1991) and Andreas von Antropoff in 1926 (before the discovery of the neutron itself) as a designation for a hypothetical element with an atomic number zero, which he placed at the beginning of the periodic table (Antropoff ,1926). A. Antropov also proposed the term "Neutronium" for the first time, although at that time this term was understood only by the yet not discovered, but already expected neutron. At the present time, both the dineutron, tetraneutrone, and octaneutron can claim this place in the PS, the information about which has already appeared in the press (Marques et al.,2012; Aleksandrov et al.,2005) and which can formally be considered as neutron isotopes. It's not difficult to see that the very substance of neutron stars, which in 1937 predicted L. D. Landau and discovered in 1968 by astronomers from Cambridge, can be considered from the point of view of the isotopy of the element Neutronium.

\section{Neutronization}

Thus, the zero position in the PS corresponds to the notion of it as a "singular point" in which to unite the micro- and mega-worlds, about the unity of which many philosophers and outstanding natural scientists have repeatedly spoken. The process of transformation of ordinary matter into neutrons under the influence of gravitational forces in the process of the evolution of certain stars was called Neutronization. The reaction of electron capture by atomic nuclei $(\mathrm{A}, \mathrm{Z})$ ( $\mathrm{A}$ is the mass number, $\mathrm{Z}$ is the order number of the element) has the form:

$$
(\mathrm{A}, \mathrm{Z})+\mathrm{e}^{-} \rightarrow(\mathrm{A}, \mathrm{Z}-1)+\mathrm{v}
$$

The energy threshold of the reaction is large, therefore, only at high material densities, characteristic of the final stages of the evolution of some stars, the electron energy may exceed the critical value of the Neutronization threshold. Gravitational neutronization is widely described and discussed in detail, but other mechanisms for the formation of neutron matter are possible, for example, condensation of ultracold neutrons (UCN) and neutronization due to a critical increase in the atomic number of the elements in the PS. First we turn to the consideration of neutronization due to a critical increase in the ordinal number of the elements in the PS. In general, the question of the "ultimate element" was repeatedly raised by different authors and has its interesting "intrigue". The final element was initially assumed to be from the "drip" model of the nucleus with $\mathrm{Z}$ slightly more than 100 , then it was shifted to the "mysterious" number of 137, passionate admirers of many well-known physicists and among them Richard Feynman, through which 137 elements even got the unofficial name "Feynmanium ". It was believed that this element is "finite" because of the uncritical use of the Bohr model of the atom for superheavy elements, when the light velocities for the orbital electrons were obtained at $\mathrm{Z}$ $=137$. The development of the quantum theory shifted the finite element beyond $\mathrm{Z}>170$. Let's consider this question in more detail. The problem of the stability of superheavy atoms was described by Zeldovich Ya. B. and Popov V. S. back in 1971. The question of the electronic structure of an atom in a supercritical nuclear charge $(Z>170)$ is of great fundamental interest. In 1928, Paul Dirac showed that in the Coulomb field of a point charge Ze the solution of the relativistic equation for an electron becomes singular for $Z=137$. Introducing the finite dimensions of the nuclear, I. Ya. Pomeranchuk and Ya. A. Smorodinsky in 1945 showed that an accurate calculation leads to a critical charge $(Z c=170)$. In the work of S. S. Gerstein and Ya. B. Zeldovich in 1969, it was assumed that, with a supercritical charge $\mathrm{Z}>\mathrm{Zc}$, a bare nucleus $\mathrm{Z}$ spontaneously emits positrons. An atom with a filled $K$ shell, with an increase in the charge of the nucleus $\mathrm{Z}>\mathrm{Zc}$ (with increasing $Z$, the internal electronic levels continue to drop, and the size of the nuclei grow) directly passes to the critical state $Z=Z c$, not emitting positrons, but by trapping the electrons by the nucleus. The authors also consider the possible contribution of the phenomenon of vacuum polarization and the production of pairs of particles and antiparticles in the field of critical nuclei.

However, we can not but make a few critical remarks:

1. With the unconditional heuristic value of the article by Zeldovich and Popov, they did not go any further they did not make a direct conclusion about the almost complete neutronization of supercritical nuclei, although they laid the groundwork for this.

2. Their conclusion (the 4th conclusion on p. 410 ) that the properties of the outer shells of an atom (which determine, in particular, Mendeleev's periodicity of chemical properties) naturally continue to the supercritical region-is questionable.

3. They underestimated the role of vacuum polarization. Although there were papers (Panchapakesan, 1971), which state that the vacuum polarization grows unboundedly at $Z \rightarrow Z c$. This contradicted their conclusions, however, in our opinion, this is closer to the truth and this leads to the inevitable and almost complete neutronization of supercritical nuclei.

Of the modern works specifying the value of the quantity Zc, we can indicate the work "New method for solving the problem $\mathrm{Z}>137$ "and determining the energy levels of hydrogen-like atoms" V.P.Neznamov and I.I.Safronov in "Advances in Physical Sciences" in 2014.

The gradual neutronization of the element nuclei is observed long before the critical value of $\mathrm{Zc}$ are reached, the average index of the ratio of the number of neutrons and protons in the nuclei of chemical elements is steadily increasing already in all periods of the PS.

\section{Proton-neutron diagram}

Qualitatively, the growth of the neutronization degree of nuclei can be well observed by extrapolating the course 
of the curve on a proton-neutron diagram if from the whole set of known elements and their isotopes choose stable and long-lived ones.

It's clear that for quantitative conclusions from the extrapolation of the diagram, it is necessary to carry out a thorough statistical analysis of the curve for the dependence $\mathrm{p}-\mathrm{n}$ for a very wide range of nuclides. What is the nature of the mathematical dependence of $p-n$ ? It can be assumed that if in the limit a neutron substance is practically only a set of neutrons, then one should expect a hyperbolic dependence and an asymptotic tendency of the curve to some limit, if there always remains a definite, albeit decreasing, fraction of the protons in the neutron matter, then we should expect a parabolic or exponential dependence.

The statistical processing was carried out by Mathcad and ORIGIN programs: both methods yielded the same result. The proton-neutron diagram for stable and longlived isotopes is best described by a quadratic polynomial: $\mathrm{y}=\mathrm{ax}^{2}+\mathrm{bx}+\mathrm{c}$, where $\mathrm{a}=0.004982, \mathrm{~b}=1.122, \mathrm{c}=-$ 1.003 for Mathcad and $\mathrm{a}=0.005, \mathrm{~b}=1.126, \mathrm{c}=-1.0034$ by ORIGIN. Thus, the dependence of $p-n$ best corresponds to a quadratic parabola, rather than to a hyperbola and an exponential, as one would expect from a "drip" nuclear model on the one hand, and on the other, indicates that there is always a residual in the neutron matter fraction of protons.

\section{Weizsäcker formula}

Additional information can be obtained from the dependence of the specific binding energy of nucleons in the atomic nucleus on their atomic mass A, which is well described by the Weizsäcker formula. Carl Friedrich von Weizsäcker obtained the semi-empirical equation for the binding energy:

$$
\mathrm{E}_{\mathrm{B}}=\alpha \mathrm{A}-\beta \mathrm{A}^{2 / 3}-\gamma \mathrm{Z}^{2} \mathrm{~A}^{-1 / 3}-\xi(\mathrm{N}-\mathrm{Z})^{2} / \mathrm{A}+\delta \mathrm{A}^{-3 / 4},
$$

Where, $\alpha=15,75 \mathrm{MeV} ; \beta=17,8 \mathrm{MeV} ; \gamma=0,71 \mathrm{MeV} ; \xi=$ $22 \mathrm{MeV} ; \delta=+34 \mathrm{MeV}$ for even-even , $\delta=0 \mathrm{MeV}$ for odd, $\delta=-34 \mathrm{Mev}$ for odd-odd, A - atomic weight.

It can be seen that with increasing $\mathrm{A}$, the Coulomb energy of repulsion of protons makes the largest contribution to the decrease in the binding energy, while the contribution of the surface energy decreases, and the energy of symmetry is not decisive. Let's try to continue Weizsäcker's dependence on supercritical nuclei.

Because of the process of almost complete neutronization and growth of sizes for supercritical nuclei, the contribution of the surface energy will be leveled, and the Coulomb repulsion will cease to increase when supercriticality is reached, which will result in the stabilization of the neutron substance and reduce the probability of its decay by some mechanism (fission, $\beta^{+}$-decay). It is necessary to consider in more detail the $\beta^{-}$- decay, which, it would seem, should be dominant with such "overloading" by neutrons.

However, the paradox of neutron matter leads to the fact that starting from a certain critical mass and size (when the path of $\beta$-electron in a neutron matter becomes smaller than the size of the matter), $\beta^{-}$- decay from the destabilizing factor becomes a significant factor of stability. There is always some residual content of the proton matter in the neutron matter, and beta-electron emitted by decayed neutron is not able to leave the neutron matter of sufficient size (larger than the path of beta-electron in it).

\section{Tamm interaction}

The emitted electron is absorbed by the remaining protons, which in turn are converted into neutrons, thus the dynamic equilibrium of the system is maintained. In fact, it corresponds to the theory of Tamm (1975), which he put forward in his time (1934) to explain the mechanism of nuclear forces for ordinary nuclei. It should be noted that his theory was not satisfactory for ordinary atoms (Tamm appreciated his "unsuccessful" theory of nuclear forces more than his Nobel work on Cherenkov radiation), but it can be realized for the neutron matter of appropriate scale (200-300 and more femtometers), giving it additional stability.

In strongly interacting systems, there are many virtual particles and all kinds of interactions that are allowed by considerations of invariance are realized. So, in our view, the "age-old" theory of exchange $\beta$-nuclear forces Tamm (e-exchange of nucleons), and not just its modification by Hideki Yukawa ( $\pi$-exchange of nucleons), still awaits its recognition (because besides the meson cloud around the nucleon there are certainly other particles) and "dominates" in the neutron matter of the Universe, ensuring its stability and wide space distribution.

An initial study of this problem was given by Frederick Hund in 1936 in the first microscopic description of the equation of state of nuclear matter in beta equilibrium in the article "The substance at very high pressures and temperatures" only if Tamm has virtual electrons, Hund realizes a beta-equilibrium of completely real particles, but most importantly, both mechanisms contribute to the stability of supercritical nuclear matter, and in strongly interacting systems there is no fundamental difference between virtual and real particles.

Another factor of additional stability of the neutron matter during the significant increase of its mass (up to a macro scale) will be the ever-increasing contribution to the gravitational interaction. Thus, we obtain a modified Weizsäcker equation for the neutron matter, which describes the main factors of its stability and the real existence in the Universe:

$$
\mathrm{E}_{\mathrm{B}}=\alpha \mathrm{A}-\beta \mathrm{A}^{2 / 3}+\tau \mathrm{A}^{\mathrm{t}}+\lambda \mathrm{A}^{1}
$$

Where, $\alpha=15.75 \mathrm{MeV} ; \beta=17.8 \mathrm{MeV} ; \tau-$ Tamm - interaction; $\lambda$ - the gravitational interaction. The parameters of equation $3(\tau, \lambda, t, 1)$ need to be clarified in the course of further research in this area.

It's namely Tamm interaction, due to nuclear $\beta$ force, confers resistance to neutron substance already on the micro-level, not just at the macro-level due to the gravitational interaction, as it is now considered to be in astrophysics!

The existence, in addition to the forces of Yukawa, of Tamm-interaction for a neutron substance, allows one to 
expect a technology for its production in terrestrial laboratory conditions, which, based on nuclear dimensions, can be called Femtotechnology. One of the directions of femtotechnology can be the study of collisions of nuclei of heavy elements, which in sum give a compound nucleus falling into the supercritical region, i.e. Zc $>170-175$, which, apart from fission, can be stabilized by the production of various pairs of particles and antiparticles in the field of supercritical nuclei, and in the case of electronpositron pairs, the electrons will be absorbed by the supercritical nucleus and positrons emit as the charge of the nucleus decreases to critical values of Zc. A detailed study of such systems will become possible after the implementation of the NICA Project (NICA, English Nuclotronbased Ion Collider facility) in Russia.

The possibility of the existence of superdense neutron nuclei was considered in the work of A. B. Migdal's "Theory of finite Fermi systems and properties of atomic nuclei" in the section: "Application of TC FS in nuclear physics" (1983). Migdal believed: "... neutron nuclei can be stable with respect to beta decay and fission, with $Z<<N$ and $N>$ $10^{3}-10^{5}$. Such nuclei could be observed in cosmic rays in the form of large fragments." Thus, A.B. Migdal proposed that neutron cores be searched for exotic tracks in photographic emulsions after exposure to cosmic rays.

\section{Ultracold neutrons}

From the Cosmos we will go down to Earth and once again we will see where it's possible to find a neutron substance here? Usually we are dealing with neutron radiation of various energies, but not with neutron matter. This was until 1968, when an experiment was conducted at the Laboratory of Neutron Physics under the guidance of the member of the USSR Academy of Sciences, Fyodor Lvovich Shapiro (1976; Ignatovich , 1996], in which the phenomenon of retention in vessels of very slow neutrons, predicted by academician Ya. B. Zeldovich. The behavior of neutrons held in vacuumed vessels is reminiscent of the behavior of a highly rarefied gas in the vessel. Such neutrons are called ultracold (UCN). The retention of UCN in the vessels attracts researchers the opportunity (longer than a single neutron flight through the experimental volume) to observe longer this elementary particle in the experimental setup, which gives a significant increase in the sensitivity and accuracy of experiments on the interaction of neutrons with fields and matter. For example, the use of UCN has made it possible to significantly omit the limit of the existence of the electric dipole moment of a neutron, necessary for testing the law of conservation of time parity, to more accurately measure the lifetime of a free neutron to $\beta$ decay. The most important feature of $\mathrm{UCN}$ is that they behave not as radiation, but as a substance and work with them as with a substance similar to a discharged inert gas. Moreover, one can study both physical and chemical properties. Physical properties are already being studied, but the question of the chemistry of UCN seems to be that the question is not even raised; by default somehow it seems obvious that they should be similar to inert gases.

It's look like the truth, but now we already know that inert gases, albeit with difficulty, enter into chemical reactions and form, albeit not stable, but chemical compounds.
Can this happen with UCN? If one assumes that Chemistry is only the interaction of the electron shells of atoms, as many believe, a categorical negative answer follows. But if under Chemistry is understood, more generally, the ability of micro (nano, pico or even femto) - objects to interact and form relatively stable compounds, then why not? Yes, neutrons do not have electric charge and free electrons, so that all ideas about possible classical chemical bonds (ionic, covalent, etc.) immediately disappear. But, neutrons have exactly a magnetic moment and perhaps an electric dipole moment, can not this serve the ability to interact with other objects and form, even if not stable, yet observable connections? For example, the interaction of a neutron with molecules of substances with an odd number of electrons is entirely possible (Serebrov et al., 2011; Ryazantsev et al., 2016). The development of new UCN sources is actively carried out worldwide, some of them are based on the use of solid deuterium at a temperature of $4.5 \mathrm{~K}$ (LANL, USA, PSI, Switzerland), and others on the accumulation of UCN in superfluid helium (KEK-RCNP-TRIUMF, Japan-Canada, ILL, France) (Serebrov et al., 2011). Similar work is being intensively carried out in Russia: The neutron laboratory at the Joint Institute for Nuclear Research (Dubna), the Petersburg Nuclear Physics Institute (PNPI), in Gatchina, is working on the creation of a high-intensity UCN source. With its help, they hope to obtain data that will provide answers to the most important questions of modern physics.

The projected source will make it possible to obtain a flux of ultracold neutrons (UCN) with a density of $10^{4} \mathrm{~cm}^{-3}$, which is many times greater than the maximum density now reached (Serebrov et al., 2011). This problem - obtaining intensive UCN fluxes - is now considered one of the priority in neutron physics. An increasing and larger increase in the density of ultracold neutrons inevitably leads to the formulation of the question of their possible condensation and the production of a condensed neutron substance in laboratory conditions similar to the cosmic one. It should be noted that G.A.Gamow first spoke about the condensation of cold neutrons (1946). Rarely mention this idea, which over time has found application in the theory of neutron stars. Gamow in 1937-38 showed that when a neutron gas is compressed, a new superdense state of matter arises. Gamow's key hypothesis: "We can anticipate that neutrons forming this comparatively cold cloud were gradually coagulating into larger and larger neutral complexes ..."

Not so long ago a decisive breakthrough was made to a new area: a radically new kind of matter, the so-called Bose condensates of the atoms of matter, was created.

Are condensate neutrons possible? Condensates, density and strength of which will be comparable to the density and strength of atomic nuclei. In other words, how close are we today to the point of creation of a cosmic neutron substance in the laboratory?

The Nobel Prize in Physics in 2001 was awarded to researchers Eric A. Cornell, Wolfgang Ketterle and Carl E. Wieman for obtaining and investigating the properties of the fifth state of matter - the Bose-Einstein condensate, they were able to get the first Bose condensate (Cornell et al., 2001). This could be done with the help of methods 
developed recently for the supercooling of particles by laser beams and a magnetic field.

The Bose condensate of atoms was obtained in a form convenient for research and laboratory analysis. Soon reports of the receipt of Bose condensates of various atoms showered from everywhere. The activity of scientists was also greatly facilitated by the fact that the facilities for obtaining Bose condensates turned out to be relatively inexpensive - experiments were in full swing in many countries. Soon, methods were also found for obtaining Bose condensates of particles of half-integer spin, fermions, whose class includes neutrons. In them, the particles are connected in pairs, then gathering in a Bose condensate. In many respects, neutrons are close to the lightest atoms. For example, the mass of a neutron is practically equal to the mass of a hydrogen atom, the Bose condensate of which was obtained by Ketterle in 1997.

But, in contrast to atomic Bose condensates, to natural compression of which under Bose condensation an electronic barrier is an irresistible obstacle, nothing can prevent the compression of the neutron Bose condensate. In such a condensate, UCN gas forms pairs with opposite spins, when the critical density and temperature are reached, will in itself shrink to near nuclear density when nuclear forces enter into the matter, forming a stable statea condensed neutron matter.

\section{Conclusions}

Thus, the neutron matter in our time is a very concrete physical reality, urgently demanding its rightful place in the PS and studying not only physical, but also chemical, and possibly even in the near future, engineering and technical properties! A neutron substance, or rather an element corresponding to it, begins (zero period) and ends (supercritical atoms) of the PS elements. The neutron substance is given stability already at the micro level due to Tamm-interaction, and not only at the macro level due to the gravitational interaction, as is now believed in astrophysics. The possibility of neutronization is shown not only because of the gravitational interaction, but also in other mechanisms (supercritical increase in the atomic number of the elements and UCN condensation), so there is a fundamental possibility of obtaining a neutron substance even under terrestrial conditions. Neutron matter is a necessary link connecting the microcosm with the macro- and megaworld, from a free neutron to neutron stars and black holes. The neutron substance is consistent with the original concept of the Periodic Law and the system put forward by Dmitri Ivanovich Mendeleev (Mendeleev, 1905; Ryazantsev et al., 2014, 2016, 2017, 2018).

\section{References}

Aleksandrov D.V., Nikol'skii E.Yu., Novatskii B.G. et al.: 2005, JETP LETTERS, 81 (2), 43-46.
Antropoff A.: 1926, Zeitschriftfur Angewandte Chemie, 39 (23), 722-725.

Dirac P.A.M.: 1928, Proc. Roy. Soc., 117, 610; 118, 341.

Gamow G.: 1946, Phys. Rev.,70, 572.

Gershtein S.S., Zel'dorovichYa.B.: 1970, Soviet Physics JETP, 30, № 2, 358-361.

Hund F.: 1936, Ergebn. Exakt. Naturwiss.15, 189.

Ignatovich V.K .: 1996, Advances in Physical Sciences, 166, 303-324.

Kikoin A.K .: 1991, Quant, № 1, 38,39,42-44.

Cornell E.A., Wiman K.E, Ketterle W.: 2001, Advances in Physical Sciences, 173,1319.

Marques F.M., Orr N.A., Achouri N.L., et al.: 2012, Phys. Rev. Lett., 109, 239201.

Mendeleev D.I.: 1905, Separate edition: "An Attempt of Chemical Understanding of the World Ether", St. Petersburg., Typolithography of M. P. Frolova,5-40.

Migdal A.B.: 1983, Theory of Finite Fermi Systems and Properties of Atomic Nuclei, second edition, revised and augmented, M .: Nauka, Main editors of physical and mathematical literature, 54.

Neznamov V.P., Safronov I.I.: 2014, Advances in Physical Sciences, 184, № 2, 200-205.

Panchapakesan N.: 1971, Phys. Lett. 35B, 522.

Pomeranchuk I.Ya., Smorodinsky Y.A.: 1945, J. Phys. USSR, 9, 97.

Ryazantsev G.B., Lavrenchenko G.K.: 2014, Technical gases, №1, 3-10.

Ryazantsev G.B., Lavrenchenko G.K.: 2016, Technical gases, №4, 41-49.

Ryazantsev G.B. : 2014, Science and Life, №2, 76-80.

Ryazantsev G.B., Khaskov M.A., Beckman I.N.: 2016, ISINN-24. 24 International Seminar on Interaction of Neutron with Nucle. Dubna: JINR, Russia, Abstrats, 71.

Ryazantsev G.B., Lavrenchenko G.K., Khaskov M.A., Beckman I.N.: 2017, ISINN-24. 24 International Seminar on Interaction of Neutron with Nucle. Dubna: JINR, Russia, Article, 65-74.

Ryazantsev G.B., Khaskov M.A., Beckman I.N., Lavrenchenko G.K.: 2017, ISINN-25. 25 International Seminar on Interaction of Neutron with Nucle.

Dubna: JINR, Russia, Abstrats, 79.

Ryazantsev G.B., Lavrenchenko G.K., Beckman I.N.: 2018, 18-th Gamow Summer School "ASTRONOMY AND BEYOND: ASTROPHYSICS, COSMOLOGY, COSMOMICROPHYSICS, ASTROPARTICLE PHYSICS, RADIOASTRONOMY AND ASTROBIOLOGY” Odessa, Ukraine, Abstrats ,15.

Shapiro F.L.: 1976, Collected Works. M.,Science, 2, 348.

Serebrov A.P., Boldarev S.T., Erykalov A.N. et al.: 2011, Physics Procedia, 17, 251-258.

Tamm I.E.: 1975, Collection of scientific works, M., Science, 1, 283-326.

Zel'dovich Ya.B., Popov V.S.: 1971, Advances in the physical sciences, 105, 403-440. 